\title{
Novel treatment options for chronic kidney disease complications
}

(D) Renato Demarchi Foresto ${ }^{1}$
(D) José Osmar Medina Pestana'

1. Hospital do Rim, São Paulo, SP, Brasil

http://dx.doi.org/10.1590/1806-9282.66.S1.1
The worldwide prevalence of renal diseases has increased in recent years due to the concomitant growth of the prevalence of its main associated risk factors, such as hypertension, diabetes, obesity, and cardiovascular diseases ${ }^{1,2}$. In particular, Chronic Kidney Disease (CKD), with an estimated prevalence of around $10 \%$ worldwide ${ }^{2}$. In Brasil, the same trend is observed, and the number of patients with end-stage renal disease undergoing dialysis surpasses 130,000 and grows every year ${ }^{3}$. Prevention and early diagnosis, combined with the proper treatment of the disease, help reduce unfavorable outcomes, generate quality of life benefits, and reduce costs related to health care ${ }^{4}$.

To meet the growing demand caused by renal diseases, there have also been many promising advances in the treatment of diseases associated with nephropathy, for example, the use of SGLT-2 inhibitors in the treatment of diabetes, with favorable results in the EMPA-REG, CANVAS, DECLARE and, more recently, CREDENCE studies regarding the progression of diabetic kidney disease, proteinuria, and cardiovascular outcomes such as mortality and hospitalization due to decompensated heart failure ${ }^{5-8}$. These benefits are gained through the glycosuria and natriuresis generated by inhibiting glucose reabsorption in the proximal tubule with oral hypoglycemic agents.
For the treatment of CKD anemia, there is also a new class of medications, the HIF-PH (Hypoxia Inducible Factor Prolyl Hydroxylase) inhibitors, which stimulate the endogenous production of erythropoietin. This new class of medications includes vadadustat, daprodustat, roxadustat, and molidustat. Clinical trials have demonstrated that these drugs are effective for treating CKD anemia with relatively fewer adverse events, such as a lower risk of cardiovascular events or thrombosis attributed to exogenous erythropoietin, besides the advantage of being oral medications, which provide higher patient adherence ${ }^{9}$.

In the same way, other therapeutic advances are noteworthy, such as the new immunosuppressants for kidney transplantation, the use of rituximab for glomerulopathies, and the technological advances focused on hemodialysis. The expectation in the area is that new knowledge will be obtained regarding the understanding of the cellular regeneration, the use of stem cells, and bioengineering to develop new strategies to restore renal function ${ }^{10}$. Additionally, the advent of the CRISPR (Clustered Regularly Interspaced Short Palindromic Repeats) genetic editing technology brings hope for the correction of genetic errors related to diseases that affect the kidneys. There are still many challenges along the way, such as the correct use of the therapy on the specific gene 
and producing hybrid animal organs for transplantation $^{11}$.

In this thematic issue, we bring a selection of reviews dedicated to the main renal diseases, such as chronic kidney disease, acute kidney injury, polycystic kidney disease, nephrotoxicity caused by medications, peritoneal dialysis, and hyperkalemia, with the latest publications in each area and also updates on the nutritional management of CKD, diabetic nephropathy and chronic kidney disease anemia.

\section{Contribution of the authors}

The authors contributed equally to the drafting and revision of this text.

\section{REFERENCES}

1. Stanifer JW, Muiru A, Jafar TH, Patel UD. Chronic kidney disease in low- and middle-income countries. Nephrol Dial Transplant. 2016;31(6):868-74.

2. Eckardt KU, Coresh J, Devuyst O, Johnson RJ, Köttgen A, Levey AS, et al. Evolving importance of kidney disease: from subspecialty to global health burden. Lancet. 2013;382(9887):158-69.

3. Brazilian Society of Nephrology (SBN) [internet]. Brazilian census of dialysis 2018. [cited 2019 Jun 7]. Available from: http://www.censo-sbn.org.br/ censosAnteriores

4. Levey AS, Eckardt KU, Tsukamoto Y, Levin A, Coresh J, Rossert J, et al. Definition and classification of chronic kidney disease: a position statement from Kidney Disease: Improving Global Outcomes (KDIGO). Kidney Int. 2005;67(6):2089-100.

5. Zinman B, Wanner C, Lachin JM, Fitchett D, Bluhmki E, Hantel S, et al. Empagliflozin, cardiovascular outcomes, and mortality in type 2 diabetes. N Engl | Med. 2015;373(22):2117-28.

6. Neal B, Perkovic V, Mahaffey KW, de Zeeuw D, Fulcher G, Erondu N, et al. Canagliflozin and cardiovascular and renal events in type 2 diabetes. N Engl Med. 2017;377(7):644-57.

7. Wiviott SD, Raz I, Bonaca MP, Mosenzon O, Kato ET, Cahn A, et al. Dapagliflozin and cardiovascular outcomes in type 2 diabetes. N Engl J Med. 2019;380(4):347-57.

8. Perkovic V, lardine MI, Neal B, Bompoint S, Heerspink HIL, Charytan DM, et al. Canagliflozin and renal outcomes in type 2 diabetes and nephropathy. N Engl | Med. 2019;380(24):2295-306.

9. Chen $N$, Hao C, Peng X, Lin H, Yin A, Hao L, et al. Roxadustat for anemia in patients with kidney disease not receiving dialysis. N Engl | Med. 2019;381(11):1001-10.

10. Oxburgh L, Carroll TI, Cleaver O, Gossett DR, Hoshizaki DK, Hubbell JA, et al. (Re)Building a kidney. J Am Soc Nephrol. 2017;28(5):1370-8.

11. Cruz NM, Freedman BS. CRISPR gene editing in the kidney. Am J Kidney Dis. 2018;71(6):874-83. 